Cahiers $d u$ MONDE RUSSE

\section{Cahiers du monde russe}

Russie - Empire russe - Union soviétique et États indépendants

$49 / 4 \mid 2008$

Destins individuels et terreur. Jeunesse dans la société post-stalinienne

\title{
Yaacov Ro'i, Boris Morozov, eds, The Soviet Union and the June 1967 Six Day War
}

\section{Marie-Pierre Rey}

\section{OpenEdition}

\section{Journals}

Édition électronique

URL : https://journals.openedition.org/monderusse/6949

DOI : 10.4000/monderusse. 6949

ISSN : $1777-5388$

Éditeur

Éditions de l'EHESS

\section{Édition imprimée}

Date de publication : 28 décembre 2008

Pagination : 763-765

ISBN : 978-2-7132-2197-2

ISSN : $1252-6576$

Référence électronique

Marie-Pierre Rey, "Yaacov Ro'i, Boris Morozov, eds, The Soviet Union and the June 1967 Six Day War », Cahiers du monde russe [En ligne], 49/4 | 2008, mis en ligne le 12 septembre 2013, consulté le 03 septembre 2022. URL : http://journals.openedition.org/monderusse/6949; DOI : https://doi.org/ 10.4000/monderusse.6949

Ce document a été généré automatiquement le 3 septembre 2022.

Tous droits réservés 


\title{
Yaacov Ro'i, Boris Morozov, eds, The Soviet Union and the June 1967 Six Day War
}

\author{
Marie-Pierre Rey
}

\section{RÉFÉRENCE}

Yaacov Ro'I, Boris MOROzov, eds, The Soviet Union and the June 1967 Six Day War.

Washington, DC : Woodrow Wilson Center Press ; Stanford : Stanford University Press, $2008,366 \mathrm{p}$.

1 L'ouvrage coordonné par Yaacov Ro'i et Boris Morozov réunit neuf contributions qui, émanant de chercheurs américains, russes et israéliens et toutes fondées sur des archives depuis peu accessibles, éclaire de manière nouvelle et convaincante la question de l'engagement et du rôle de l'Union soviétique durant la guerre des Six Jours.

Cinq articles présentés dans le volume traitent directement de l'attitude soviétique à l'heure du conflit. Le premier, rédigé par Yaacov Ro'i, traite de l'engagement soviétique dans la guerre des Six Jours en l'analysant au travers du prisme des relations soviétosyriennes et soviéto-égyptiennes et montre de manière convaincante l'ampleur des difficultés rencontrées par Moscou: alors que les leaders soviétiques espéraient influencer leurs alliés au mieux de leurs intérêts, ils furent en réalité obligés de composer avec les aspirations de ces derniers et finalement contraints de soutenir un conflit armé qu'ils espéraient éviter. Le second article, écrit par Boris Morozov, fait écho au précédent et s'intéresse à l'attitude de l'URSS au moment du déclenchement du conflit : il souligne que le Kremlin avança à reculons vers la guerre, soucieux d'éviter coûte que coûte une confrontation militaire directe avec les États-Unis dans la région. Le troisième, rédigé par Yair Even, se livre de manière stimulante à une étude comparée de l'engagement de l'URSS dans les conflits de 1956 et de 1967 et en conclut que Moscou sortit nettement affaiblie de la guerre des Six Jours alors même que la guerre du Sinaï et la crise de Suez 
avaient conforté les positions soviétiques au Moyen-Orient. Enfin, Mikhail Monakov présente une étude très neuve sur la présence navale soviétique en Méditerranée durant la guerre et souligne combien l'objectif soviétique - s'assurer une présence permanente et neutraliser la supériorité stratégique américaine - fut difficile à mettre en œuvre.

Les autres contributions du volume déplacent le point de vue. L'article de Jeremi Suri traite des perceptions américaines de l'attitude soviétique avant et pendant le conflit, ainsi que de leurs conséquences sur la gestion de la crise par Washington. Alors qu'initialement préoccupée par la guerre du Vietnam, l'administration Johnson n'accordait qu'une importance marginale à la crise au Moyen-Orient, la nature du conflit et son enjeu - dans un contexte encore largement marqué par la guerre froide, lequel des deux supergrands prendrait l'ascendant dans la région? - conduisirent peu à peu les États-Unis à s'immiscer dans la crise et à finalement en tirer avantageusement parti. L'article de Shaul Shay, qui traite des perceptions israéliennes, souligne que Tel-Aviv se résolut à prendre le risque d'un affrontement direct, tout en redoutant la réaction du Kremlin et en surestimant les capacités militaires soviétiques.

Enfin les trois derniers textes s'intéressent aux conséquences du conflit. Privilégiant l'exemple de la Bulgarie, celui de Jordan Baev traite de la mobilisation à laquelle, au lendemain de la guerre, les pays d'Europe de l'Est ont été soumis de la part de Moscou pour promouvoir de bonnes relations avec les pays arabes considérés désormais comme des «États progressistes ». Consacré à l'intervention militaire soviétique dans la guerre d'usure qui se joue en 1969-1970 entre l'Égypte et Israël, l'article de Dima Adamsky montre que cette intervention fut largement le résultat du fiasco de la guerre des Six Jours, les Soviétiques voulant désormais contrôler la situation militaire pour éviter qu'elle ne leur échappe de nouveau. Pour finir, un second article de Yaacov Ro'i traite des effets internes du conflit en évoquant les réactions des Juifs soviétiques durant le conflit : nombre d'entre eux éprouvèrent en effet un sentiment de profonde sympathie envers Israël et la période vit l'émergence d'une nouvelle sensibilité sioniste en URSS.

Les neuf contributions sont encadrées par une stimulante introduction de Yaacov Ro'i et une conclusion rédigée à deux voix par Yaacov Ro'i et Dima Adamsky. Enfin, et ce n'est pas le moindre intérêt du volume, au texte lui-même ( 280 pages) s'ajoutent, en appendice, douze documents représentant près de 70 pages, qui, tous tirés d'archives soviétiques ou est-européennes récemment accessibles, constituent un passionnant corpus de sources.

6 À quelles conclusions majeures les auteurs ont-ils abouti? Plusieurs d'entre eux soulignent que l'engagement de l'URSS dans la guerre des Six Jours a largement précédé la guerre elle-même et qu'il était inextricablement lié aux relations complexes que Moscou entretenait alors avec la Syrie et l'Égypte. Les textes convergent pour démontrer que si, dès le mois de mai 1967, les leaders soviétiques ont cherché à tirer avantage de la crise qui se nouait et ont joué avec le feu pour apparaître comme des acteurs incontournables de la scène moyen-orientale (en effet, à ce moment, ils sont allés jusqu'à diffuser de fausses informations, annonçant à tort aux services égyptiens et syriens qu'Israël avait commencé à masser des troupes à la frontière syrienne), ils ne souhaitaient pas pour autant déclencher un conflit armé. Et, très vite, déstabilisés par ce qu'ils percevaient comme de l'aventurisme de la part de Nasser, les leaders soviétiques ont eu à cœur d'éviter tout engagement direct dans la guerre. Ils se contentèrent de soutenir leurs alliés en les approvisionnant en armes tout en engageant des discussions avec Washington, afin de terminer la guerre au plus tôt, préfigurant ainsi le 
condominium soviéto-américain qui devait s'affirmer de manière plus nette lors du nouveau conflit israélo-arabe de 1973. L'ouvrage met aussi en relief de manière très neuve que la guerre des Six Jours contribua à souder les démocraties populaires autour de Moscou, puisque ces dernières furent sommées de soutenir économiquement et militairement les pays belligérants. Enfin, les contributions soulignent également combien, en dépit de l'engagement de l'URSS et de la mobilisation forcée des démocraties populaires, le bilan de la crise fut décevant pour Moscou: alors que le Kremlin escomptait de la crise un rayonnement et une autorité accrues au Moyen-Orient, la déroute militaire de ses alliés lui compliqua singulièrement la tâche. Certes, au lendemain de la guerre, les liens avec la Syrie et l'Égypte furent renforcés, et l'envoi de conseillers et de spécialistes militaires soviétiques (2000 environ dans chaque pays à la fin de l'année 1967, près de 20000 en Égypte en 1972) s'accrût sensiblement. Mais cette présence n'éteignit pas tous les doutes et les relations avec les pays arabes restèrent chaotiques tandis que l'image de l'URSS, puissance protectrice, se dégradait dans le reste du Tiers-Monde. En 1972, l'expulsion des conseillers soviétiques signa la rupture soviétoégyptienne et, dans un contexte de défiance réciproque, constitua pour Moscou un nouveau camouflet qui attestait la difficulté des Soviétiques à promouvoir, face à des alliés insaisissables, une politique moyen-orientale cohérente et pérenne. 